\title{
Predictive Factors to Diagnose Appendicitis in Children in the Emergency Department
}

\section{Ar-aishah Dadeh (ID \\ Kamolnut Puitong}

Department of Emergency Medicine, Songklanagarind Hospital, Faculty of Medicine, Prince of Songkla University, Hat Yai, Songkhla, 901 I0, Thailand
Correspondence: Ar-aishah Dadeh Department of Emergency Medicine, Songklanagarind Hospital, Faculty of Medicine, Prince of Songkla University, Hat Yai, Songkhla, 901 I0, Thailand Tel +66 74-45I 705

Fax +66 74-45I704

Email dadehstou@gmail.com
Introduction: The most common surgical condition in children is appendicitis. However, making a diagnosis can be difficult due to poor communication and difficulty in the physical examination.

Objective: This study aimed to determine the accurate clinical predictive factors for the diagnosis of appendicitis in children in the emergency department (ED).

Methods: A retrospective cohort study was conducted from January 2015 to December 2019. The electronic medical records were reviewed from 1043 pediatric patients younger than 15 years with the chief complaint of abdominal pain and were admitted to the ED during the study period. The patients were divided into either the appendicitis group or non-appendicitis group. The two groups were compared in terms of baseline characteristics, abdominal symptoms and signs, symptom durations, laboratory results, final diagnosis, treatment in the ED, ED disposition, morbidity, and mortality. The significant predictive factors for the diagnosis of appendicitis were examined using univariate and multivariate analyses by logistic regression.

Results: Predictive factors for the diagnosis of appendicitis in pediatric patients with abdominal pain were gradual increase in abdominal pain (odds ratio (OR) 3.38, 95\% confidence interval (CI) 1.51-7.58), right lower quadrant abdominal tenderness (OR 21.07, 95\% CI 9.12-48.67), presentation of peritoneal irritation signs (OR 12.57, 95\% CI 5.2829.92 ), and an absolute neutrophil count $>75 \%$ (OR 4.68, 95\% CI 2.3-9.51). The significant variables were used to develop a diagnostic predictive probability scoring system that ranged from 0.05 to 0.95 . The receiver operating characteristic curve indicated a cut-off point of 0.089 to predict pediatric appendicitis with an area under the curve of 0.963 .

Conclusion: The predictive factors for diagnosing appendicitis in children are useful in determining which children require surgical intervention. However, the clinical symptoms and physical examination of the abdomen continue to be the most important diagnostic tools for the diagnosis of appendicitis in children.

Keywords: appendicitis, abdominal pain, diagnosis, children

\section{Introduction}

Abdominal pain is a common symptom in children but often there are limitations in determining the diagnostic cause of abdominal pain between surgical and medical conditions. Due to obstacles in communication and physical examination, the diagnosis and management in young patients can be a challenge. ${ }^{1}$ Appendicitis is the most common surgical emergency in children. The peak ages for appendicitis in children are between 9 and 12 years with a male predominance. ${ }^{2}$ On average, one child was diagnosed with appendicitis in 15 children with abdominal pain, and onethird of children were diagnosed with perforated appendicitis which perforated 
before receiving treatment. ${ }^{3}$ Especially in young children who cannot communicate well, a lack of communication was found to increase the rate of perforated appendix. In pediatric patients younger than 3 years, the appendicitis rupture rate was as high as $80-100 \%$, and the appendicitis rupture rate was $38 \%$ in older children. ${ }^{4}$ A delayed diagnosis increases the risk of perforated appendicitis which increases postoperative complications. Furthermore, a perforated appendix increases the time of hospital stay, costs, risk of in-hospital infection, morbidity, and mortality. ${ }^{5}$ However, the diagnosis is relatively difficult because the signs and symptoms are often not as straightforward as those found in adults. Furthermore, poor communication and limited physical examinations in children make it difficult to distinguish appendicitis from other causes of abdominal pain that are not surgical conditions. A misdiagnosis on initial presentation ranged from $28 \%$ to $57 \%$ in children younger than 12 years. $^{5}$

Several scoring systems have been documented in past decades and most of them were derived from clinical presentations, physical signs, and laboratory tests. The Alvarado score and Pediatric Appendicitis Score (PAS) are commonly used in pediatric patients. ${ }^{6}$ The Alvarado score was first published in 1986 and has proved to be helpful in the diagnosis of acute appendicitis in the adult and pediatric populations around the world. ${ }^{7}$ A systematic review demonstrated an Alvarado score of 8-9 or higher rules in the diagnosis. ${ }^{7,8}$ The PAS is simple and provides a relatively accurate diagnostic tool to assess an acute abdomen and diagnose appendicitis in children. ${ }^{9}$ In 2008 Andersson et al constructed the Appendicitis Inflammatory Response (AIR) score based on clinical signs and symptoms and laboratory tests that included the C-reactive protein (CRP) and white blood cell count (WBC) results. ${ }^{10}$ One prospective observational study presented the validity of the AIR score in distinguishing pediatric appendicitis patients with simple and perforated appendicitis with $89.5 \%$ sensitivity and $71.9 \%$ specificity by using a cut-off value of $9 .{ }^{11}$ In contrast to the Alvarado and PAS scores, the AIR score uses CRP as one of the variables in detecting inflammatory response or process. ${ }^{11}$ Moreover, recent studies explored the ability of hyponatremia and hyperbilirubinemia as discriminative markers of complicated appendicitis. However, hyponatremia was studied only in the pediatric population, whereas hyperbilirubinemia was studied in both pediatric and adult patients. ${ }^{12,13}$

Ultrasonography and abdominal computed tomography (CT) are currently used to help diagnose appendicitis.
However, these tools cause a delayed diagnosis and a CT scan includes the disadvantage of radiation exposure which increases the likelihood of cancer in children by up to 1 per 1000 people. $^{9}$

This study aimed to determine the accurate clinical predictive factors for the diagnosis of acute appendicitis in pediatric patients who present with abdominal pain.

\section{Materials and Methods}

\section{Study Design and Setting}

A retrospective cohort study was conducted in the emergency department (ED) of Songklanagarind Hospital, which is a teaching hospital and a tertiary care medical center with a capacity of 850 beds and has an ED volume of over 48,000 patient visits per year. The data were collected from January 1, 2015 to December 31, 2019. The inclusion criteria were pediatric patients aged younger than 15 years who presented to the ED with acute abdominal pain. The exclusion criteria of the pediatric patients were intra-abdominal organ disease, previous abdominal surgery, prior diagnosis of cancer, and incomplete medical records. A total of 1,043 patients were included in the retrospective study.

\section{Data Collection}

The data collected from the electronic medical records and ED data registry included baseline characteristics, medical history at presentation, physical examination findings, duration of symptoms, laboratory and imaging results, final diagnosis, treatment in the ED, ED disposition, morbidity, and mortality. The patients were divided into either the appendicitis group or non-appendicitis group. Appendicitis was defined by a surgical pathologic finding obtained from surgery.

\section{Outcome Measurements}

The primary outcome was to determine accurate predictive factors for the diagnosis of acute appendicitis in pediatric patients who presented with abdominal pain. Secondary outcomes were the prevalence of pediatric appendicitis, morbidity, and all hospital mortality.

\section{Statistical Analysis}

The study population sample size was calculated using the n4Studies program to test two independent proportions. All data were entered into EpiData version 3.1 and the statistical analysis was conducted using R software version 4.0.2 (The 
R Foundation, Vienna, Austria). The continuous variables were analyzed and reported as mean and median while categorical variables are reported as percentage. The Student's $t$-test was used for continuous and ordinal variables and the Pearson's Chi-squared test was used for categorical variables. A multivariate logistic regression model was used to evaluate the predicting factors for diagnosed appendicitis. We determined the predicting factors for a diagnosis of appendicitis by backward stepwise logistic regression. Significant factors associated with a diagnosis of appendicitis $(p<0.2)$ identified during univariate logistic regression analysis were introduced into a subsequent multivariate logistic regression analysis. A diagnostic predictive probability nomogram model was constructed. The optimal cut-off points to predict the score were calculated from the best sensitivity and specificity. The cut-off point value of the predictive score to predict diagnosis of appendicitis was calculated using receiver operating characteristic (ROC) curves and area under the ROC curve (AUROC). Model discrimination was considered to be good if it yielded an AUROC of 0.7-0.8 and excellent if it yielded an AUROC of $0.8-0.9 .^{14}$ A $p$-value $<0.05$ was considered statistically significant. Analytical results are described as odds ratio (OR) with $95 \%$ confidence interval $(\mathrm{CI})$.

\section{Compliance with Ethical Requirements}

The ethics committee of Prince of Songkla University approved this study. The institutional review board of Prince of Songkla University is affiliated with the International Conference on Harmonization in Good Clinical Practice. According to our institutional review board protocol for waiver of informed consent, the requirement for consent was waived because the participants had no more than minimal risk and the patients received standard treatment procedures. All research information was kept as confidential data in an encrypted file with password and limited data access by only the researcher and assistant. The ethical registration number was REC.62-442-20-4. This study was conducted in accordance with the Declaration of Helsinki.

\section{Results}

\section{Demographic Data}

During the study period, 1,043 patients met the enrollment criteria. The baseline characteristics of the enrolled patients are shown in Table 1. There were 565 (54\%) males and $478(46 \%)$ females. Factors that were significantly different between the appendicitis group and non-appendicitis group included age, body measurements (weight and height), and morbidity (intraoperative adhesion, abdominal collection, and compromised hemodynamics). The median ages in the appendicitis and nonappendicitis groups were 10 and 4 years, respectively. Therefore, the weight and height values of both groups of patients had direct variations according to the age group. The appendicitis group tended to have greater weight and height values than the non-appendicitis group. The abdominal imaging results for both ultrasonography and CT scans and ED disposition are shown in Table 2. Other important diagnoses in the non-appendicitis group were intussusception, pelvic abscess, enterocolitis, cholelithiasis, and abdominal wall cellulitis. Six patients in the appendicitis group were referred to other facilities due to insurance coverage policies. The diagnosis and pathological results for these patients were confirmed by telephone. Another 6 patients in the appendicitis group were discharged from the ED by a pediatric surgeon after the initial evaluation and were followed up the next day. All patients in the appendicitis group underwent appendectomy; $40 \%$ were open surgery and $60 \%$ had a laparoscopic approach.

\section{Predictive Factors for the Diagnosis of Appendicitis}

Three significant symptoms increased the likelihood of appendicitis: migratory right lower quadrant (RLQ) pain (OR 20.898, 95\% CI 13.01-33.57), increased pain on movement (OR 18.247, 95\% CI 12.444-26.755), and gradual onset of abdominal pain (OR 3.164, 95\% CI 2.786-3.593) (Table 3). On physical examination, the presence of peritoneal signs had the highest impact on the likelihood of appendicitis (OR 45.512, 95\% CI 25.294-81.891). The presence of RLQ tenderness (OR 14.124, 95\% CI 10.876-18.343) also increased the likelihood of appendicitis. An absolute neutrophil count (ANC) $>75 \%($ OR 2.374, 95\% CI 2.055-2.743) and a neutrophil-to-lymphocyte ratio (NLR) $>3.5$ doubled the odds of appendicitis (OR 2.031, 95\% CI 1.8072.282). Multivariate analysis revealed that the significant factors for appendicitis were RLQ tenderness and presence of peritoneal signs. Although gradual onset of abdominal pain tripled the odds of appendicitis, it was not statistically significant (Table 4). 
Table I Baseline Characteristics of the Patients

\begin{tabular}{|c|c|c|c|}
\hline & Appendicitis $(n=97)$ & Non-Appendicitis $(n=946)$ & $P$-value \\
\hline Age, year, median (IQR) & $10(8,12)$ & $4(1,7)$ & $<0.001$ \\
\hline Preschool age 3-5-year-old & $8(8.2)$ & $616(65.1)$ & $<0.001$ \\
\hline School age 6-8-year-old & $23(23.7)$ & $138(14.7)$ & 0.026 \\
\hline Preadolescent age 9-12-year-old & $47(48.5)$ & $140(14.8)$ & $<0.001$ \\
\hline Adolescent age 13-18-year-old & $19(19.6)$ & $52(5.5)$ & $<0.001$ \\
\hline Gender & & & 0.397 \\
\hline Male & 57 & 508 & \\
\hline Female & 40 & 438 & \\
\hline Weight (kg), median (IQR) & $35(25,48)$ & $15(11,24)$ & $<0.001$ \\
\hline Height (cm), median (IQR) & $142(127,151)$ & $102(85,124.8)$ & $<0.001$ \\
\hline Underweight (BMI $<14.5 \mathrm{~kg} / \mathrm{m}^{2}$ ) & $25(25.8)$ & $361(38.2)$ & 0.022 \\
\hline Normal (BMI $\left.14.5-18 \mathrm{~kg} / \mathrm{m}^{2}\right)$ & $31(32)$ & $4 I I(43.4)$ & 0.038 \\
\hline Overweight (BMI > $\left.18-19.5 \mathrm{~kg} / \mathrm{m}^{2}\right)$ & $6(6.2)$ & $60(6.3)$ & 1.000 \\
\hline Obese $\left(\mathrm{BMI}>19.5 \mathrm{~kg} / \mathrm{m}^{2}\right)$ & $35(36.1)$ & $114(12.1)$ & $<0.001$ \\
\hline Duration & & & 0.146 \\
\hline$<24$ hours & $54(55.7)$ & $448(47.4)$ & \\
\hline$>24$ hours & $43(44.3)$ & $498(52.6)$ & \\
\hline Morbidity and Mortality & $8(8.2)$ & $33(3.5)$ & 0.043 \\
\hline Wound infection & 0 & 0 & \\
\hline Other organ infections & 0 & 12 & 0.111 \\
\hline Adhesion (from intraoperative note) & 5 & 0 & $<0.001$ \\
\hline Abdominal collection & 2 & 0 & 0.042 \\
\hline Sepsis & 2 & 6 & 1.000 \\
\hline Septic shock & 0 & 5 & 0.567 \\
\hline Respiratory failure & I & 9 & 0.679 \\
\hline Hemodynamically compromised & 0 & 20 & 0.007 \\
\hline Death & 0 & 4 & 0.71 \\
\hline
\end{tabular}

Note: Data are presented as $\mathrm{n}(\%)$ unless otherwise indicated.

Abbreviations: IQR, interquartile range; CT, computed tomography; ED, emergency department; BMI, body mass index for age, underweight is below the 5th percentile, normal is $\geq 5$ th and $<85$ th percentile, overweight $\geq 85$ th $-<95$ th percentile, obese $\geq 95$ th percentile for age, gender, and height.

\section{Patient Outcome, Morbidity, and Mortality}

The prevalence of appendicitis in this present study was $9.3 \%$. Morbidity and mortality were significantly different between the two groups (Table 1). The percentages of patients admitted to the hospital, referred, and discharged in the appendicitis group were $87.6 \%, 6.2 \%$, and $6.2 \%$, respectively. Intraoperative adhesion and abdominal collection were observed in the complicated appendicitis group and all had symptom durations of abdominal pain $>24$ hours. Meanwhile, the non-appendicitis group had more hemodynamically compromised patients than the appendicitis group (Table 1). After hospital admission, four patients in the non-appendicitis group died due to dengue shock syndrome, typhlitis, upper gastrointestinal bleeding, and acute gastroenteritis.

\section{Nomogram Construction and Predictive Performance}

The scoring system to predict diagnosis of appendicitis was developed based on significant variables. Each factor was assigned a score and the sum of the score was converted to a probability in the total points axis. A score greater than 80 points suggested a diagnosis of appendicitis and a score greater than 210 points had a high probability for a diagnosis of appendicitis (Figure 1). The optimal cut-off score point was 0.089 for a high probability to predict a diagnosis of appendicitis with an AUROC of 0.963 . If the score is more than 0.05 , it can predict a diagnosis of appendicitis (Figure 2). A comparison of clinical risk scores used in clinical practice to diagnose appendicitis and our score are shown in Table 5. 
Table 2 Comparison of Abdominal Imaging Results and Dispositions

\begin{tabular}{|c|c|c|c|}
\hline & Appendicitis $(n=97)$ & Non-Appendicitis ( $n=946)$ & $P$-value \\
\hline \multicolumn{4}{|l|}{ Abdominal Imaging } \\
\hline Ultrasonography & $46(47.4)$ & $60(6.3)$ & $<0.001$ \\
\hline Computed tomography & $15(15.5)$ & $6(0.6)$ & $<0.001$ \\
\hline \multicolumn{4}{|l|}{ Abdominal ultrasound finding } \\
\hline Evidence of appendicitis & 28 & 2 & $<0.001$ \\
\hline No evidence of appendicitis & 3 & 13 & \\
\hline Cannot see normal appendix & 12 & 25 & \\
\hline Other findings & 3 & 20 & \\
\hline - Intussusception & 0 & 14 & \\
\hline - Pelvic abscess & 3 & 0 & \\
\hline - Cholelithiasis & 0 & 2 & \\
\hline - Enterocolitis & 0 & 3 & \\
\hline - Abdominal wall cellulitis & 0 & I & \\
\hline \multicolumn{4}{|l|}{ Abdominal CT finding } \\
\hline Evidence of appendicitis & 15 & 0 & $<0.001$ \\
\hline No evidence of appendicitis & 0 & 1 & \\
\hline Other findings & 0 & 5 & \\
\hline - Meckel's diverticulitis & 0 & 2 & \\
\hline - Perforated gastric tumor & 0 & 1 & \\
\hline - Bleeding mesenteric tumor & 0 & 1 & \\
\hline - Ruptured corpus luteal cyst & 0 & I & \\
\hline \multicolumn{4}{|l|}{ ED Disposition } \\
\hline Admitted & $85(87.6)$ & $282(29.8)$ & $<0.001$ \\
\hline Referred & $6(6.2)$ & $40(4.2)$ & \\
\hline Discharged & $6(6.2)$ & $624(66)$ & \\
\hline
\end{tabular}

Note: Data are presented as $\mathrm{n}(\%)$ unless otherwise indicated.

Abbreviations: CT, computed tomography; ED, emergency department.

\section{Discussion}

The statistically significant accurate factors associated with a diagnosis of appendicitis after the multivariate logistic regression analysis were RLQ tenderness and presence of peritoneal irritation signs. However, two other significant factors identified only in the univariate analysis were gradual onset of abdominal pain and an ANC $>75 \%$. Both of these factors were considered to be clinical prediction variables and were introduced into the calculated score.

The classic presenting symptoms of appendicitis in children begin with anorexia and vague periumbilical abdominal pain. ${ }^{1}$ However, our study found that those classic symptoms had low accuracy to diagnose appendicitis. Most appendicitis patients experience abdominal pain which is classically described as migrating to the RLQ. ${ }^{1}$ Migratory pain to the RLQ presented with a high positive likelihood ratio for appendicitis in our study. Other symptoms with high positive likelihood ratios identified in this study were increased pain on movement and gradual onset of abdominal pain. However, young children have limited ability describing these symptoms. We found that gradual onset of abdominal pain had high sensitivity and specificity in the diagnosis of appendicitis. The clinical risk scores that are currently used, such as the Alvarado and PAS scores, do not include gradual onset of abdominal pain as a rating factor. A comparison of our score constructed from the best sensitivity and specificity and the other practical clinical risk scores is shown in Table 5.

On physical examination RLQ tenderness and presence of peritoneal irritation signs, such as rebound tenderness, cough, or percussion tenderness, increased the likelihood of appendicitis. However, our results contrasted with those reported in an observational study by Becker et al which concluded that $50 \%$ of those with appendicitis presented without pain migration and $50 \%$ without rebound tenderness. ${ }^{15}$ 
Table 3 Accuracy of Symptoms, Signs, and Laboratory Results

\begin{tabular}{|c|c|c|c|c|}
\hline Variables & Sensitivity & Specificity & $\begin{array}{l}\text { Positive Likelihood Ratio } \\
(95 \% \mathrm{Cl})\end{array}$ & $\begin{array}{l}\text { Negative Likelihood Ratio } \\
(95 \% \mathrm{Cl})\end{array}$ \\
\hline \multicolumn{5}{|l|}{ Symptoms } \\
\hline Vague periumbilical pain & 0.619 & 0.665 & $\mathrm{I} .846(\mathrm{I} .54 \mathrm{I}-2.2 \mathrm{I})$ & $0.574(0.443-0.742)$ \\
\hline Anorexia & 0.443 & 0.574 & $1.04 \mid(0.823-1.316)$ & $0.97(0.805-1.168)$ \\
\hline Increasing pain on movement & 0.598 & 0.967 & 18.247 (I2.444-26.755) & $0.416(0.326-0.53)$ \\
\hline Migratory to RLQ & 0.464 & 0.978 & $20.898(|3.0|-33.57)$ & $0.548(0.455-0.66)$ \\
\hline Gradual onset of abdominal pain & 0.876 & 0.723 & $3.164(2.786-3.593)$ & $0.171(0.101-0.291)$ \\
\hline Nausea and vomiting & 0.268 & 0.786 & $1.255(0.884-1.783)$ & $0.931(0.82 I-1.055)$ \\
\hline \multicolumn{5}{|l|}{ Signs } \\
\hline Fever & 0.474 & 0.641 & $1.319(1.052-1.654)$ & $0.821(0.675-0.997)$ \\
\hline Tachycardia & 0.876 & 0.217 & $1.119(1.031-1.214)$ & $0.57 \mid(0.332-0.983)$ \\
\hline RLQ tenderness & 0.866 & 0.939 & $14.124(10.876-18.343)$ & $0.143(0.086-0.237)$ \\
\hline Peritoneal signs & 0.577 & 0.987 & $45.512(25.294-81.891)$ & $0.428(0.339-0.54)$ \\
\hline \multicolumn{5}{|l|}{ Laboratory results } \\
\hline ANC $>75 \%$ & 0.763 & 0.679 & $2.374(2.055-2.743)$ & $0.349(0.244-0.501)$ \\
\hline Leukocytosis & 0.753 & 0.541 & $\mathrm{I} .64(\mathrm{I} .435-1.875)$ & $0.457(0.322-0.65)$ \\
\hline$N L R>3.5$ & 0.835 & 0.589 & $2.031(1.807-2.282)$ & $0.28(0.178-0.44)$ \\
\hline$M P V<9 \mathrm{fl}$ & 0.907 & 0.242 & $1.196(1.112-1.287)$ & $0.383(0.203-0.721)$ \\
\hline WBC or $\mathrm{RBC}$ in urine $>5$ cell/HPF & 0.062 & 0.952 & $1.3(0.569-2.97)$ & $0.985(0.934-1.039)$ \\
\hline
\end{tabular}

Abbreviations: $\mathrm{Cl}$, confidence interval; RLQ, right lower quadrant; ANC, absolute neutrophil count; NLR, neutrophil-to-lymphocyte ratio; MPV, mean platelet volume; WBC, white blood cell; RBC, red blood cell; HPF, high power field.

Table 4 Multivariate Logistic Regression Analysis of Predictive Factors for the Diagnosis of Appendicitis

\begin{tabular}{|c|c|c|c|c|}
\hline & Crude OR $(95 \% \mathrm{Cl})$ & $P$-value & Adjusted OR (95\% Cl) & $P$-value \\
\hline \multicolumn{5}{|l|}{ Symptoms } \\
\hline Vague periumbilical pain & $3.16(2.05-4.86)$ & $<0.001$ & $1.3(0.6-2.82)$ & 0.532 \\
\hline Increasing pain on movement & $43.18(25.13-74.18)$ & $<0.001$ & $1.09(0.28-4.26)$ & 0.937 \\
\hline Migratory pain to the RLQ & $37.5(20.82-67.55)$ & $<0.001$ & $1.49(0.59-3.77)$ & 0.432 \\
\hline Gradual onset of abdominal pain & $18.38(9.88-34.2)$ & $<0.001$ & $3.1(1.28-7.52)$ & 0.12 \\
\hline \multicolumn{5}{|l|}{ Signs } \\
\hline Fever & $1.63(1.07-2.49)$ & 0.022 & $1.46(0.67-3.18)$ & 0.365 \\
\hline Tachycardia & $0.5 \mathrm{I}(0.27-0.95)$ & 0.033 & $0.73(0.27-1.95)$ & 0.532 \\
\hline RLQ pain & 97.26 (51.19-184.77) & $<0.001$ & $21.07(9.12-48.67)$ & $<0.001$ \\
\hline Peritoneal signs & $104.6(52.07-210.13)$ & $<0.001$ & $9.46(2.15-41.66)$ & 0.003 \\
\hline \multicolumn{5}{|l|}{ Laboratory results } \\
\hline Leukocytosis & $3.62(2.24-5.85)$ & $<0.001$ & $1.58(0.68-3.65)$ & 0.235 \\
\hline \multicolumn{5}{|l|}{ WBC $>10-000$ if duration of pain $<24$ hours } \\
\hline \multicolumn{5}{|l|}{ WBC $>14-000$ if duration of pain $>24$ hours } \\
\hline NLR $>3.5$ & $7.24(4.17-12.58)$ & $<0.001$ & $1.8(0.49-6.62)$ & 0.415 \\
\hline ANC >75\% & $6.8(4.18-11.08)$ & $<0.001$ & $2.21(0.68-7.23)$ & 0.175 \\
\hline MPV <9 fl & $0.33(0.16-0.67)$ & 0.002 & $0.37(0.13-1.1)$ & 0.059 \\
\hline
\end{tabular}

Abbreviations: $\mathrm{Cl}$, confidence interval; RLQ, right lower quadrant; WBC, white blood cells; RBC, red blood cells; NLR, neutrophil-to-lymphocyte ratio; ANC, absolute neutrophil count; MPV, mean platelet volume; fl, femtoliter.

The laboratory studies usually performed to assess the overall state of inflammation or body response to infection include the WBC count, ANC, NLR, and mean platelet volume (MPV). ${ }^{16-18}$ The results of the present study showed that those markers have wide ranges in sensitivity and specificity in predicting appendicitis and were compatible with previous studies. ${ }^{9,19,20}$ Moreover, leukocytosis is often used in scoring systems to diagnose appendicitis 


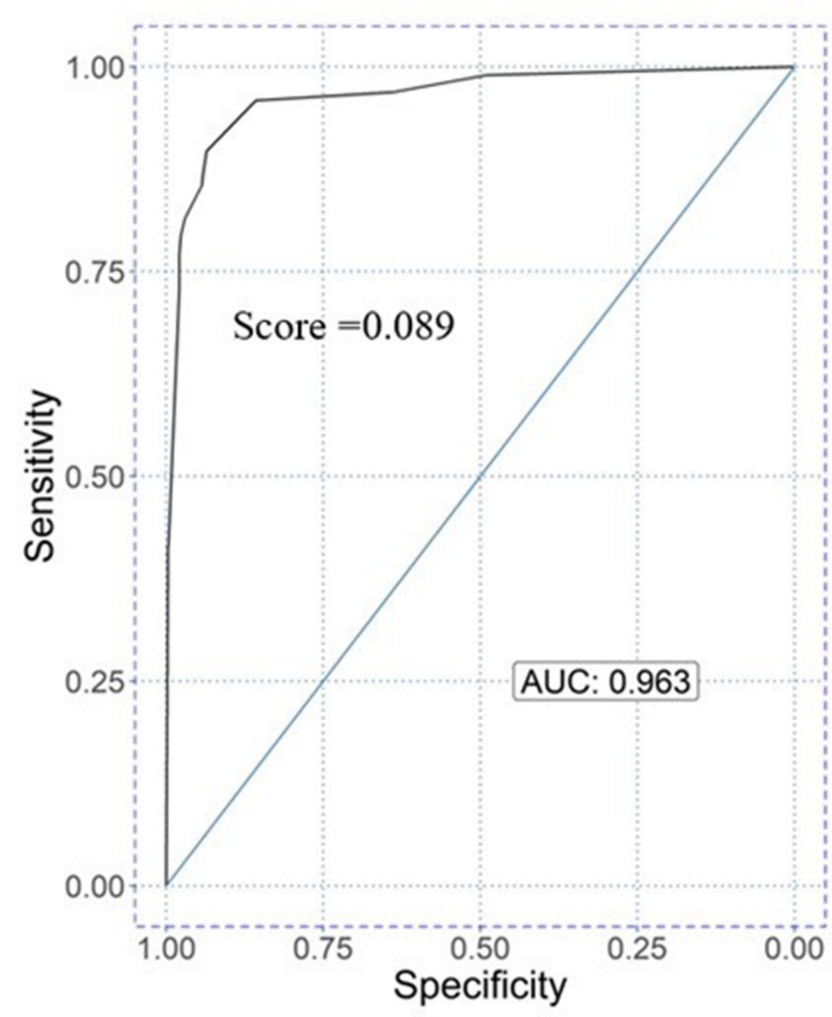

Figure I Receiver operating characteristic curve of cut-off point score for predicted appendicitis.

Abbreviation: AUC, area under the curve.

both in children and adult patients. ${ }^{9,19,21}$ However, a normal leukocyte count does not exclude appendicitis and a markedly elevated leukocyte count $(>16,000$ cell/ $\mathrm{mm}^{3}$ ) suggests perforation or other conditions such as gastroenteritis, mesenteric adenitis, pelvic inflammatory disease, and numerous infectious disorders. ${ }^{5,22}$ Our study demonstrated that an ANC $>75 \%$, which doubled the odds of appendicitis, was compatible with a previous study by Kwan et al. ${ }^{23}$ A study by Prasetya reported that the NLR showed high accuracy to diagnose acute appendicitis and distinguished a complicated appendicitis from a simple one. ${ }^{18} \mathrm{MPV}$ relates to the activation and activity of platelets in the blood system. ${ }^{17,24}$ Danese et al concluded that inflammatory bowel disease decreased the MPV because more blood platelets are used in the blood vessels that feed the inflamed intestines. ${ }^{24}$ Another study by Bilici et al indicated that the MPV decreased significantly in pediatric appendicitis patients. Hence, they believed that taking the MPV decrease into consideration along with the WBC count elevation would be beneficial in patients with suspicion of appendicitis. ${ }^{25}$ However, the present study found no difference in the MPV values between the appendicitis and non-appendicitis groups. Moreover, our study showed a higher MPV value in the appendicitis group than in the non-appendicitis group which was compatible with a study by Narci et al. ${ }^{26}$

Diagnostic imaging plays an important role in determining appendicitis according to the data from one children's hospital that demonstrated low negative appendectomy rates when diagnostic imaging was used. ${ }^{22}$ Although ultrasonography has various sensitivities ranging from $73 \%$ to $100 \%$ and specificities between $80 \%$ and $97 \%$ depending on operator experience, ${ }^{23}$ it is a widely used modality by emergency physicians because it lacks radiation exposure. Positive evidence of appendicitis was
Points

Gradual onset

RLQ tenderness

Peritoneal irritation

ANC $>75 \%$ of $\mathrm{WBC}$

Total Points

Diagnostic Predictive Probability

\section{FALSE}

\section{FALSE}
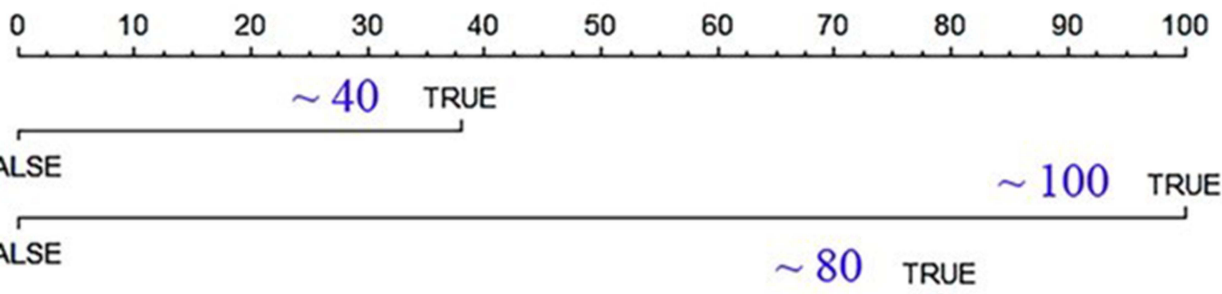

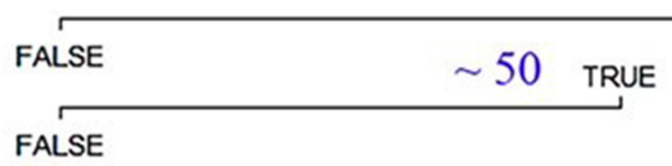

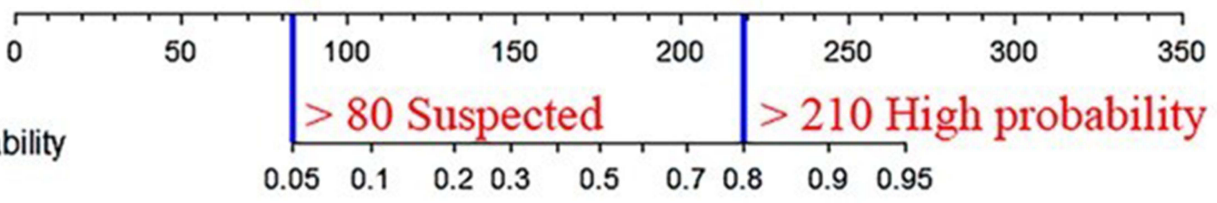

Figure 2 Nomogram to diagnose appendicitis based on symptoms, signs, and laboratory results. 
Table 5 Comparison of Clinical Risk Scores and the Score Constructed by the Present Study

\begin{tabular}{|c|c|c|c|c|}
\hline Factors & $\begin{array}{l}\text { Alvarado } \\
\text { Score }\end{array}$ & $\begin{array}{l}\text { Modified Alvarado } \\
\text { Score }\end{array}$ & PAS & $\begin{array}{l}\text { This } \\
\text { Study }\end{array}$ \\
\hline Migratory of pain to RLQ & I & 1 & 1 & - \\
\hline Anorexia & I & 1 & 1 & - \\
\hline Nausea/Vomiting & I & I & 1 & - \\
\hline Tenderness in RLQ & 2 & 2 & 2 & 100 \\
\hline $\begin{array}{l}\text { Rebound tenderness (PAS: cough/percussion tenderness or hopping } \\
\text { tenderness) }\end{array}$ & 1 & 1 & 2 & 80 \\
\hline Gradually onset of abdominal pain & - & - & - & 40 \\
\hline Fever $\mathrm{BT}>38^{\circ} \mathrm{C}$ & 1 & 1 & 1 & - \\
\hline $\begin{array}{l}\text { Leukocytosis } \\
\text { - Alvarado score and Modified Alvarado score: WBC >10,400 } \\
\text { - PAS: WBC >10,000 }\end{array}$ & 2 & 2 & 1 & - \\
\hline Shifted WBC count & 1 & - & 1 & - \\
\hline ANC $>75 \%$ & - & - & - & 50 \\
\hline Total score & 10 & 9 & 10 & 270 \\
\hline Probable appendicitis & $\geq 7$ & $\geq 7$ & $\geq 6$ & $>80$ \\
\hline
\end{tabular}

Abbreviations: PAS, Pediatric Appendicitis Score; RLQ, right lower quadrant; BT, body temperature; WBC, white blood cells; ANC, absolute neutrophil count.

identified in only $32.6 \%$ of all ultrasonography results in the present study. A CT scan provides more accurate information for making a diagnosis. However, the concern of increased malignancy risk due to ionizing radiation has placed ultrasonography as the first imaging modality of choice. A CT scan should be used only when ultrasonography cannot provide sufficient information to make a diagnosis of appendicitis. ${ }^{22}$ Rather than simply identifying appendicitis, both ultrasound and CT findings demonstrate the cause of abdominal pain in children.

The mortality rate of appendicitis in children ranges from $0.1 \%$ to $1 \%$. It was reported that several independent factors, such as age younger than 5 years, symptom duration longer than 24 hours, hyponatremia, and leukocytosis, predicted complicated appendicitis in children, which led to mortality. ${ }^{27}$ Hospital mortality was not found in the appendicitis group in this study.

We must acknowledge the limitations of the present study. First, the study was retrospective in nature which was conducted in a single ED and some data may be missing. Second, all patients in the appendicitis group presented with abdominal pain. Thus, our research did not demonstrate any patients with an atypical presentation of appendicitis. Third, our clinical score was constructed from the data of this study and cannot be generalized to the general pediatric population.

\section{Conclusions}

The clinical symptoms, physical abdominal signs, and ANC are useful in determining which children require surgical intervention. This study showed that the predictive factors for diagnosing appendicitis in children were gradual increase in abdominal pain, RLQ abdominal tenderness, presentation of peritoneal irritation signs, and ANC $>75 \%$. However, we emphasize that the clinical symptoms and performing the physical examination of the abdomen are important for diagnosing appendicitis in children.

\section{Data Sharing Statement}

The retrospective data used to support the findings of this study are available from the corresponding author upon request.

\section{Acknowledgments}

The authors thank Kingkarn Waiyanak for searching and retrieval of articles, Glenn K. Shingledecker for his help in editing the manuscript, the Epidemiology Unit for their 
assistance, and the Faculty of Medicine for funding this research.

\section{Author Contributions}

All authors made a significant contribution to the work reported, whether that is in the conception, study design, execution, acquisition of data, analysis and interpretation, or in all these areas; took part in drafting, revising or critically reviewing the article; gave final approval of the version to be published; have agreed on the journal to which the article has been submitted; and agree to be accountable for all aspects of the work.

\section{Disclosure}

The authors report no conflicts of interest in this work.

\section{References}

1. Sullins VF, Lee SL. Appendicitis. In: Holcomb G, Murphy JP, St Peter S, editors. Ashcraft's Pediatric Surgery. 6th ed. Philadelphia, PA: Elsevier; 2019:568.

2. Fleischman RJ. Acute abdominal pain in infants and children. In: Tintinalli JE, Ma OJ, Yealy DM, et al., editors. Tintinalli's Emergency Medicine: A Comprehensive Study Guide. 9th ed. New York: McGraw-Hill; 2020.

3. Erikci VS. Management of pediatric appendicitis. In: Garbuzenko DV, editor. Current Issues in the Diagnostics and Treatment of Acute Appendicitis. 1st ed. London, UK: IntechOpen; 2018:77-90.

4. Smith J, Fox SM. Pediatric abdominal pain: an emergency medicine perspective. Emerg Med Clin North Am. 2016;34(2):341-361. doi:10.1016/j.emc.2015.12.010

5. Rothrock SG, Skeoch G, Rush JJ, Johnson NE. Clinical features of misdiagnosed appendicitis in children. Ann Emerg Med. 1991;20 (1):45-50. doi:10.1016/S0196-0644(05)81117-5

6. Pogorelić Z, Rak S, Mrklić I, Jurić I. Prospective validation of Alvarado score and Pediatric Appendicitis score for the diagnosis of acute appendicitis in children. Pediatr Emerg Care. 2015;31 (3):164-168. doi:10.1097/PEC.0000000000000375

7. Alvarado A. How to improve the clinical diagnosis of acute appendicitis in resource limited settings. World J Emerg Surg. 2016;11:16. doi:10.1186/s13017-016-0071-8

8. Ebell MH, Shinholser JA. What are the most clinically useful cutoffs for the Alvarado and Pediatric Appendicitis scores? A systematic review. Ann Emerg Med. 2014;64(4):365-372. doi:10.1016/j. annemergmed.2014.02.025

9. Samuel M. Pediatric appendicitis score. J Pediatr Surg. 2002;37 (6):877-881. doi:10.1053/jpsu.2002.32893

10. Andersson M, Andersson RE. The appendicitis inflammatory response score: a tool for the diagnosis of acute appendicitis that outperforms the Alvarado score. World $J$ Surg. 2008;32 (8):1843-1849. doi:10.1007/s00268-008-9649-y

11. Pogorelić Z, Mihanović J, Ninčević S, Lukšić B, Elezović Baloević S, Polašek O. Validity of appendicitis inflammatory response score in distinguishing perforated from non-perforated appendicitis in children. Children. 2021;8(4):309.
12. Pogorelić Z, Lukšić $B$, Ninčević $S$, Lukšić $B$, Polašek $O$. Hyponatremia as a predictor of perforated acute appendicitis in pediatric population: a prospective study. J Pediatr Surg. 2020. doi:10.1016/j.jpedsurg.2020.09.066

13. Bakshi S, Mandal N. Evaluation of role of hyperbilirubinemia as a new diagnostic marker of complicated appendicitis. $B M C$ Gastroenterol. 2021;21(1):42. doi:10.1186/s12876-021-01614-x

14. Kim J, Hwang IC. Drawing guidelines for receiver operating characteristic curve in preparation of manuscripts. J Korean Med Sci. 2020;35(24):e171. doi:10.3346/jkms.2020.35.e171

15. Becker T, Kharbanda A, Bachur R. Atypical clinical features of pediatric appendicitis. Acad Emerg Med. 2007;14(2):124-129. doi:10.1197/j.aem.2006.08.009

16. D'Alessandro DM, D'Alessandro MP. What causes tachycardia? Pediatric digital library intended to serve as a source of continuing pediatric education [Internet].2020 [cited 2021 March 6]. Available from: https://pediatriceducation.org/2020/03/23/what-causes-tachy cardia/.

17. Kapsoritakis AN, Koukourakis MI, Sfiridaki A, et al. Mean platelet volume: a useful marker of inflammatory bowel disease activity. Am J Gastroenterol. 2001;96(3):776-781. doi:10.1111/ j.1572-0241.2001.03621.x

18. Prasetya D, Rochadi G. Accuracy of neutrophil lymphocyte ratio for diagnosis of acute appendicitis in children: a diagnostic study. Ann Med Surg. 2019;48:35-38. doi:10.1016/j.amsu.2019.10.013

19. Bond GR, Tully SB, Chan LS, Bradley RL. Use of the MANTRELS score in childhood appendicitis: a prospective study of 187 children with abdominal pain. Ann Emerg Med. 1990;19(9):1014-1018. doi:10.1016/S0196-0644(05)82566-1

20. Benito J, Acedo Y, Medrano L, Barcena E, Garay RP, Arri EA. Usefulness of new and traditional serum biomarkers in children with suspected appendicitis. Am J Emerg Med. 2016;34 (5):871-876. doi:10.1016/j.ajem.2016.02.011

21. Kalan M, Talbot D, Cunliffe WJ, Rich AJ. Evaluation of the modified Alvarado score in the diagnosis of acute appendicitis: a prospective study. Ann R Coll Surg Engl. 1994;76(6):418-419.

22. Peter S, Wester T. Appendicitis. In: Holcomb GW, Murphy JP, Peter SD, editors. Ashcraft's Pediatric Surgery. 7th ed. Philadelphia, PA: Elsevier; 2020:664-673.

23. Kwan KY, Nager AL. Diagnosing pediatric appendicitis: usefulness of laboratory markers. Am J Emerg Med. 2010;28(9):1009-1015. doi:10.1016/j.ajem.2009.06.004

24. Danese S, De La Motte C, Fiocchi C. Platelets in inflammatory bowel disease: clinical, pathogenic, and therapeutic implications. $\mathrm{Am}$ $J \quad$ Gastroenterol. 2004;99(5):938-945. doi:10.1111/j.15720241.2004.04129.x

25. Bilici S, Sekmenli T, Göksu M, Melek M, Avci V. Mean platelet volume in diagnosis of acute appendicitis in children. Afr Health Sci. 2011;11(3):427-432.

26. Narci H, Turk E, Karagulle E, Togan T, Karabulut K. The role of mean platelet volume in the diagnosis of acute appendicitis: a retrospective case-controlled study. Iran Red Crescent Med J. 2013;15(12):e11934. doi:10.5812/ircmj.11934

27. Pham XD, Sullins VF, Kim DY, et al. Factors predictive of complicated appendicitis in children. J Surg Res. 2016;206(1):62-66. doi:10.1016/j.jss.2016.07.023 


\section{Publish your work in this journal}

The Open Access Emergency Medicine is an international, peerreviewed, open access journal publishing original research, reports, editorials, reviews and commentaries on all aspects of emergency medicine. The manuscript management system is completely online and includes a very quick and fair peer-review system, which is all easy to use. Visit http://www.dovepress.com/testimonials.php to read real quotes from published authors.

Submit your manuscript here: https://www.dovepress.com/open-access-emergency-medicine-journal 